\title{
COMPUTATIONAL STUDIES OF SOME BISCOUMARIN AND BISCOUMARIN THIOUREA DERIVATIVES AS $\alpha$-GLUCOSIDASE INHIBITORS
}

\author{
M. T. IBRAHIM ${ }^{1 *}$, A. UZAIRU ${ }^{1}$, G. A. SHALLANGWA ${ }^{1}$ AND A. IBRAHIM ${ }^{1}$ \\ ${ }^{1}$ Department of Chemistry Ahamadu Bello University, P.M.B. 1044, Zaria Nigeria. \\ ${ }^{*}$ Corresponding author. Ahamadu Bello University, Department of Chemistry, Zaria, Kaduna, Nigeria, Phone: +2348069651985 \\ e-mail address1: muhdtk1988@gmail.com (M. T. Ibrahim).
}

\section{A R T I C L E I N F O}

\section{Article history: \\ Received 2018-04-11 \\ Accepted 2018-05-27 \\ keywords \\ $\alpha$-glucosidase \\ QSAR \\ Molecular docking \\ Biscoumarin}

Available online 2018-06-30

\section{A B S T R A C T}

Quantitative structure-activity relationship (QSAR) and molecular docking studies of 35 compounds of Biscoumarins and Biscoumarins thiourea derivatives as $\alpha$-glucosidase inhibitors was performed. Density Functional Theory (DFT) method was employed for complete geometry optimization of the $\alpha$-glucosidase inhibitors. Genetic Function Algorithm (GFA) of the material studio was utilized to develop four models. Model 1 was found to be the best model with $R^{2}=0.914362, R_{\text {adj }}^{2}=0.892953, Q_{c v}^{2}=0.858197$ and $R_{\text {pred }}^{2}=$ 0.614745 . The proposed model is robustness and predicted with good internal and external validation. The descriptors should be considered when improving the inhibitory activities of biscoumarin derivatives against $\alpha$-glucosidase. The docking results showed that ligands having Ortho substituted phenyl ring have good interactions with active site residues and good inhibitory activities as compared to ligands having either Para or Meta substituted phenyl ring except ligand 16 which has the highest docking scores of $-12.5 \mathrm{kcal} / \mathrm{mol}$ but undergoes para substitution on the phenyl ring and formed hydrogen bond, hydrophobic and electrostatic interactions with the active residues of the enzyme. The QSAR model and molecular docking results agree with each other and give way to the designing of new inhibitors with better activity against $\alpha$-glucosidase. 


\section{INTRODUCTION}

$\alpha$-glucosidase (EC.2.2.1.20) is an important enzyme that plays a crucial role in the metabolism of carbohydrates in the body. It speeds up the decomposition of glycosidic bonds in the non-reducing carbohydrate end, causing the release of excess glucose in the digestive tract of the body. It is located in the membranous tissue of the small intestine (Wang et al., 2016b). $\alpha$-glucosidase inhibitors are classes of drugs used to treat type 2 diabetes by inhibition of $\alpha$-glucosidase (Taha et al., 2015). $\alpha$-glucosidase inhibitors are useful in the management of type 2 diabetes by preventing the decomposition of carbohydrates and thus reducing hyperglycemia (Kavitha et al., 2017). $\alpha$-glucosidase inhibitors can prevent viral infections in the body such as HIV, hepatitis, and cancer (Li et al., 2004).

Biscoumarin is a dimeric type of coumarin with effective inhibitory activities (Aziz et al., 2013). Natural and synthetic Biscoumarin have diverse biological activities which include antifungal, anti-inflammatory, and antioxidant activities (Khan et al., 2014).

Computer-aided drug design is very important for mechanisms of action, experimental results and a new indication for synthesizing new molecules and can help reduce costs and save time in drug development (Bibi and Sakata, 2016) A large number of molecules have been identified using the computational method and have gotten to a clinical stage for drug development (Talele et al., 2010). With the increase in computational power, an in-silico study has led to the development of new active drugs with a fewer side effect. QSAR and molecular docking studies were carried out to predict the activities of various compounds and elucidate the specific areas where interaction may decrease or increase the activity of the inhibitor molecules (Amit et al., 2014); (Boukarai et al., 2017); (Wang et al., 2016a). QSAR establish a relationship between properties of various molecules and their biological activities while molecular docking is an insilico method that helps in elucidating the interaction between the drug and protein (Abdulfatai et al., 2017). This research focused on developing a QSAR model that will predict the activities of Biscoumarin derivatives against $\alpha$-Glucosidase receptor and carry out molecular docking studies between the inhibitor compounds and $\alpha$-Glucosidase receptor.

\section{MATERIALS AND METHOD}

\subsection{QSAR studies}

Dataset collection: 35 sets of Biscoumarin and Biscoumarin thiourea derivatives and their inhibitory activities against $\alpha$-glucosidase were gotten from the literature (Zawawi et al., 2015) and (Khan et al., 2014) and used for this study. The inhibitory activities of these compounds calculated as $\mathrm{IC}_{50}$ $(\mu \mathrm{M})$ were converted to $\mathrm{pIC}_{50}\left(\mathrm{pIC}_{50}=\log 1 / \mathrm{IC}_{50}\right)$. The structures and the inhibitory activities of these molecules were shown in Table 1 . The $\alpha$-Glucosidase inhibitory activities of these molecules range from 1.13 to $2.59(\mu \mathrm{M})$ as expressed in $\mathrm{pIC}_{50}$ logarithm scale.

Table 1- Shows the structures and the activity $\left(\mathrm{pIC}_{50}\right)$ of the dataset.

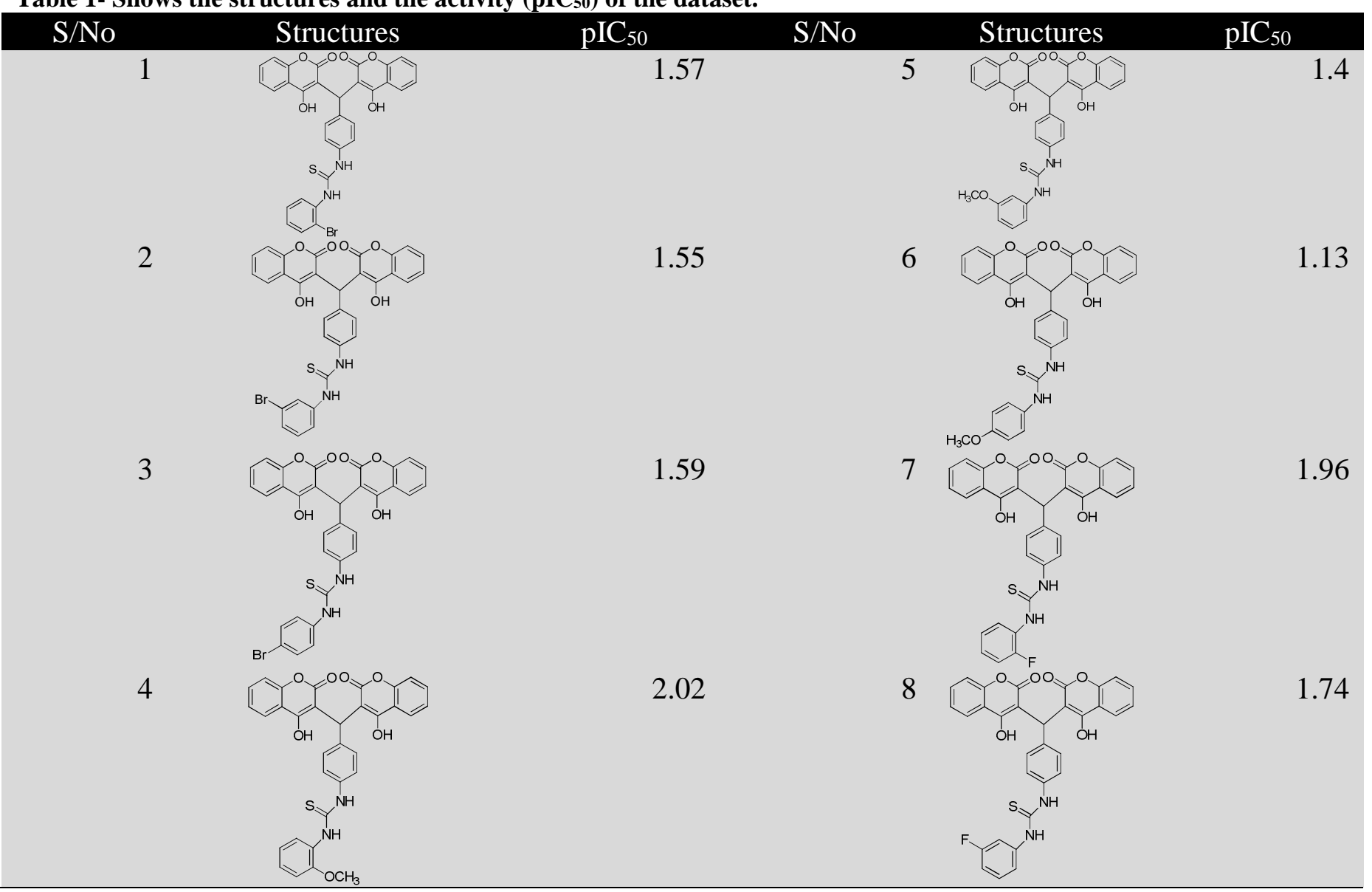


Continued Table 1

\section{S/No}

9

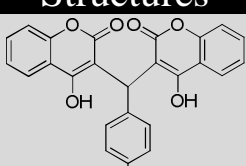

$\mathrm{pIC}_{50}$

1.73

S/No

17

Structures

OH

1.71

10
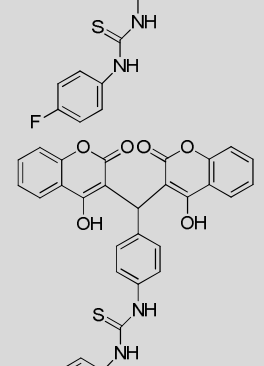

11

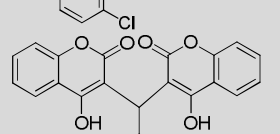

12<smiles>CCOc1cccc(Cl)c1</smiles>

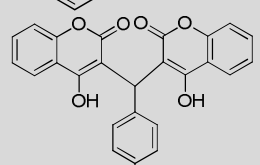

$v^{\mathrm{H}}$

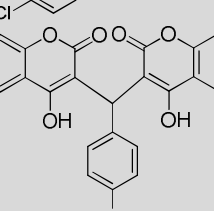

Sy $y^{\mathrm{NH}}$

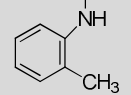

14

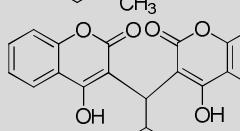

1.89

1.7

1.45

19
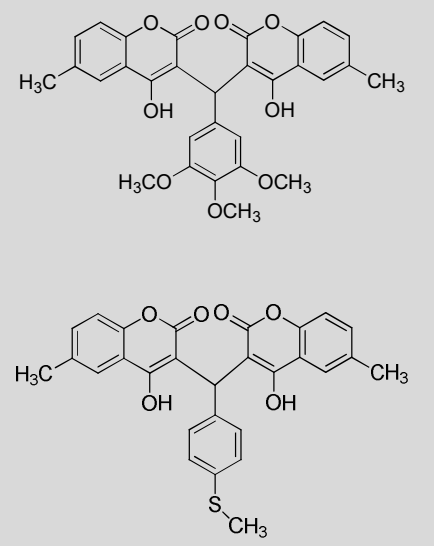

21

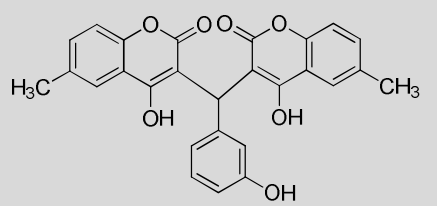

1.72

22

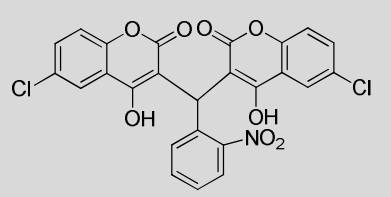

1.64

23

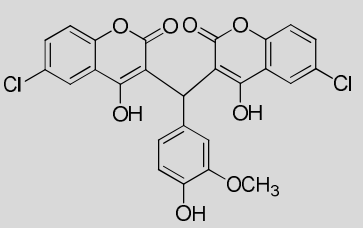

1.5

24

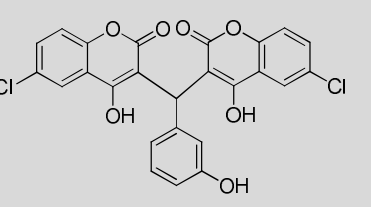




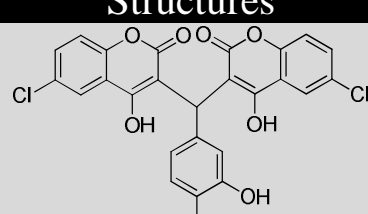

26
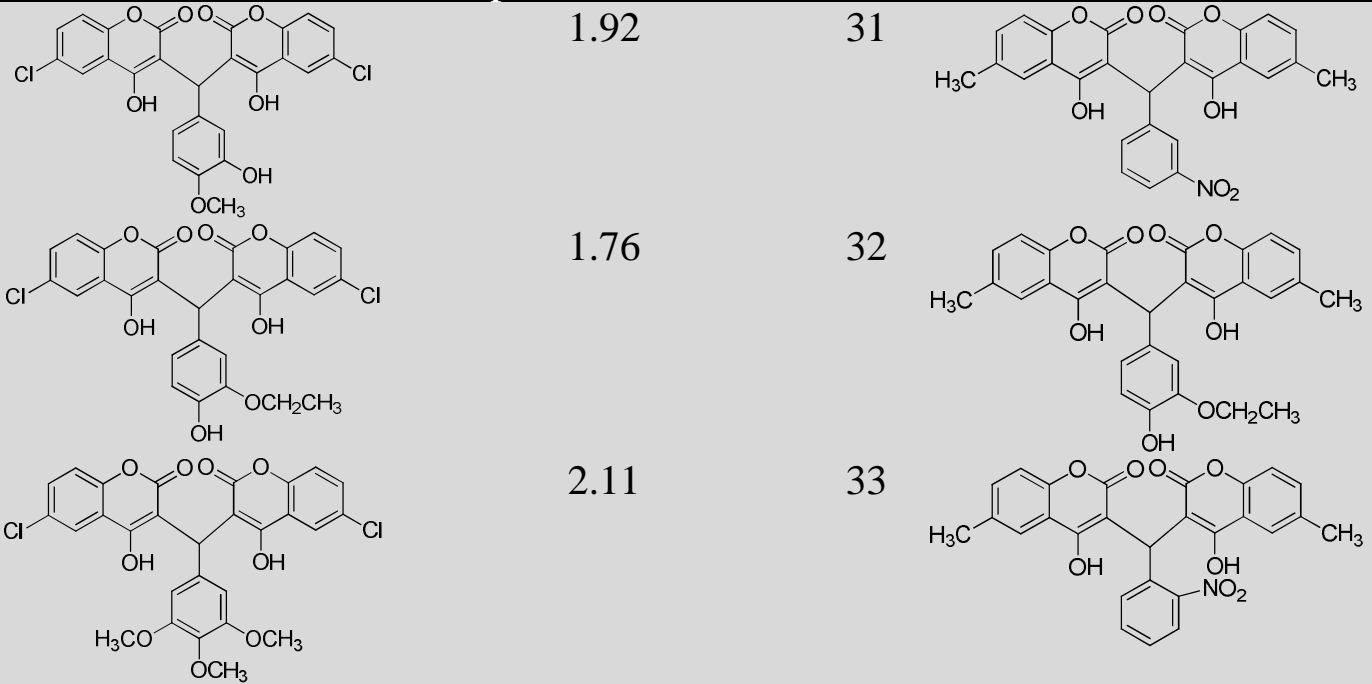<smiles>Cc1ccccc1</smiles><smiles></smiles>

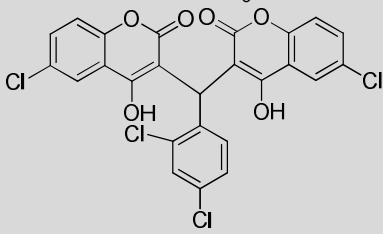

30
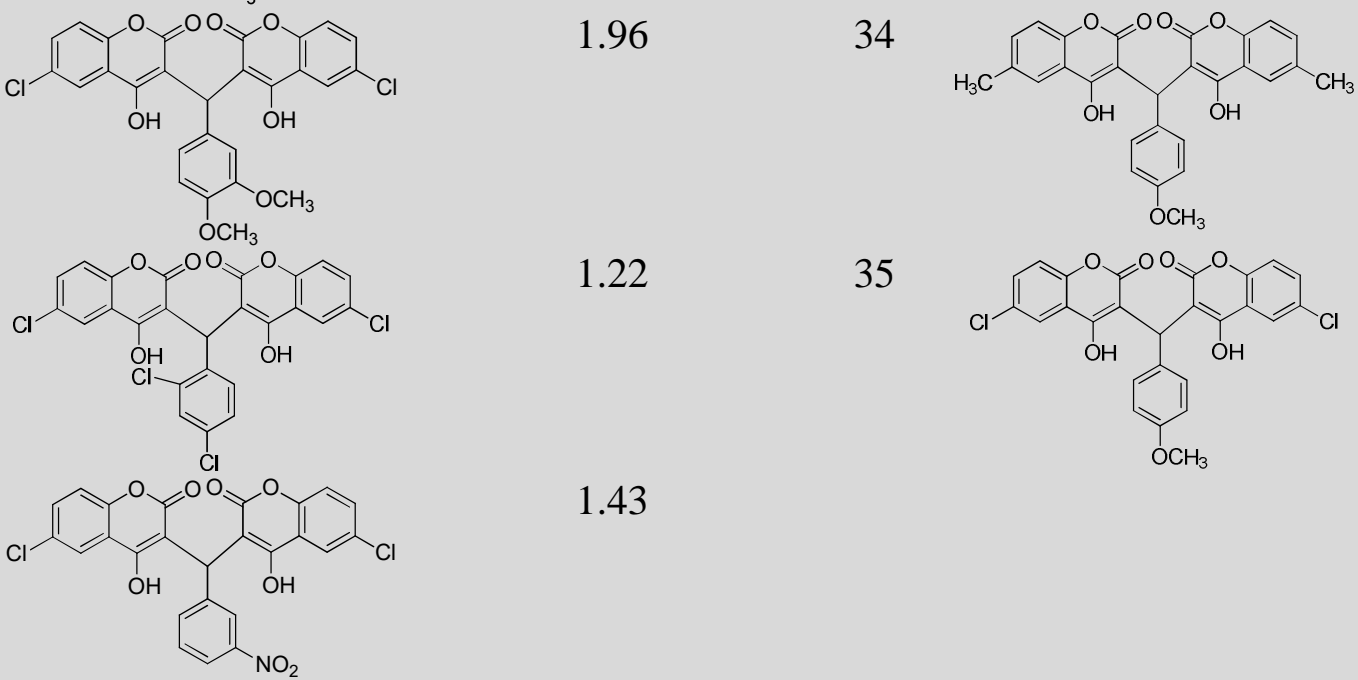

Geometry Optimization: ChemDraw Ultra version 12.0 software was used to draw the 2D structure of the compounds and save as cdx file format. The structures were then converted to 3D using Spartan 14.0 version 1.1.2 software. Density functional theory (DFT) using the B3LYP version and 6$311 \mathrm{G}^{*}$ basis set, was employed for complete geometry optimization of the structures (Abdulfatai et al., 2016).

Molecular Descriptors calculation: 0D, 1D, 2D and 3D descriptors were calculated using PaDEL descriptor software version 2.18 and saved as sdf file format from the optimized structures of the Spartan files, (Yap, 2011).

Dataset division: Kennard-Stone Algorithm was used to split the dataset into training and test set using (Kennard and Stone, 1969). $75 \%$ of the dataset goes to the training set used and the remaining $25 \%$ as the test sets used for external validation of the built model.

Model Building: Regression analysis was performed using Genetic Function Algorithm (GFA) method in material studio software with the biological activities $\left(\mathrm{pIC}_{50}\right)$ as the dependent variable and the physicochemical properties (descriptors) as independent variables.

Internal validations: The built models were assessed using Friedman's Lack of Fit (LOF) which served as a measure of fitness of a model. Below is the revised formula for the Friedman's lack of fit.

$$
L O F=\frac{S E E}{\left(1-\frac{C+d p}{M}\right)^{2}}
$$

where SEE is the standard error of estimation, $p$ is the total number of descriptors in the model, $d$ is a user-defined smoothing parameter, $\mathrm{c}$ is the number of terms in the model, and $\mathrm{M}$ is the number compound in the training set.

SEE is the standard error of estimation which equals to the standard deviation of the model and a model is said to be good when it has lower SEE value. SEE is given as:

$$
S E E=\sqrt{\frac{\left(Y_{\text {exp }}-Y_{\text {pred }}\right)^{2}}{N-P-1}}
$$

The structure of the regression model takes the form(Arthur et al., 2016)

$$
Y=a 1 \times 1+a 2 \times 2+a 3 \times 3+b
$$

where $\mathrm{Y}$ is the biological activity $\left(\mathrm{pIC}_{50}\right)$, ' $\mathrm{a}$ 's are regression coefficients for the corresponding ' $x$ 's which are the independent variables representing molecular descriptors of the molecules, the last variable 'c' is the regression constant. 
$\mathrm{R}^{2}$ gives an account of the fragment of total variation of the model. The nearer the $\mathrm{R}^{2}$ value is to 1.0 , the better the model developed. The most frequently used internal assessment parameter for QSAR model is $\mathrm{R}^{2}$ and is shown below:

$$
R^{2}=1-\frac{\sum\left(Y_{\text {exp }}-Y_{\text {prd }}\right)^{2}}{\sum\left(Y_{\text {exp }}-Y_{m n t r n g}\right)^{2}}
$$

where $Y_{\exp }, Y_{\text {pred }}$, and $Y_{\text {mntraining }}$ are the observed activity, the predicted activity and the average observed activity of the training set (Adeniji et al., 2018).

Adjusted $\mathrm{R}^{2}\left(\mathrm{R}^{2}\right.$ adj $)$ value changes directly with an increament in the number of descriptors; $\mathrm{R}^{2}$ is not suitable for measuring the stability of a model. In order to have a reliable and stable model, $\mathrm{R}^{2}$ needs to be adjusted. The adjusted $\mathrm{R}^{2}$ is defined as follows:

$$
R^{2}=1-\left(1-R^{2}\right) \frac{(n-1)}{n-p-1}=\frac{(n-1)\left(R^{2}-P\right)}{n-p+1}
$$

Where $\mathrm{n}$ is the number of compounds in the training set, $\mathrm{p}=$ number of descriptors in the model (Abdulfatai et al., 2017).

The cross-validation coefficient $\left(\mathrm{Q}_{\mathrm{cv}}{ }^{2}\right)$ is used to determine the power of a QSAR model to predict the activity of new compounds. $\mathrm{Q}_{\mathrm{cv}}{ }^{2}$ is represented as:

$$
Q_{c v}^{2}=1-\frac{\sum\left(Y_{p r d}-Y_{\text {exp }}\right)^{2}}{\sum\left(Y_{\text {exp }}-Y_{\text {mntrng }}\right)^{2}}
$$

where $\mathrm{Y}_{\text {pred }}$ and $\mathrm{Y}_{\exp }$ represent the predicted and experimental activity $\left(\mathrm{pIC}_{50}\right)$ respectively of the training set and $\mathrm{Y}_{\mathrm{mntrng}}$ the average activity value of the training set(Jalali-Heravi and Kyani, 2004).

External validation: The external validation of the generated model is based on the $\mathrm{R}^{2}$ test value and is defined as:

$$
R_{\text {test }}^{2}=1-\frac{\sum\left(Y_{\text {prd }}-Y_{\text {exp }}\right)^{2}}{\sum\left(Y_{\text {exp }}-Y_{m n t r n g}\right)^{2}}
$$

where $\mathrm{Y}_{\text {pred }}$ and $\mathrm{Y}_{\exp }$ represent the predicted and biological activity $\left(\mathrm{pIC}_{50}\right)$ respectively of the test set and $\mathrm{Y}_{\mathrm{mntrng}}$ the mean activity value of the test set (Tropsha et al., 2003).

Applicability domain: Applicability domain of a QSAR model is employed to determine outliers and influential compounds and to affirm the reliability and robustness of the model generated (Tropsha et al., 2003). Leverage is one of the techniques used in evaluating the applicability domain of a QSAR model and is given for a chemical compound as $h_{i}$ :

$$
h_{i}=x_{i}\left(X^{T} X\right)^{-K} x_{i}^{T} \quad(i=K, \cdots, P)
$$

where $x_{i}$ is the training compound matrix $I, \mathrm{X}$ is $n \times k$ descriptor matrix of the training set compounds and $X^{T}$ is the transpose matrix $X$ used to build the model. As a prediction tool, the warning leverage $\left(h^{*}\right)$ which is the limit for $\mathrm{X}$ values and it's defined as:

$$
h^{*}=\frac{3(p+1)}{n}
$$

where $n$ is the number of training compounds, and $\mathrm{p}$ is the number of descriptors in the model.
Y-randomization Test: In Y-randomization test, random Multi Linear regrasion models are built by randomly moving the activity while keeping the descriptors unchanged. The $R^{2}$ and $Q^{2}$ values for the new QSAR models built for many trials are expected to be very low, which confirm that the developed QSAR models are robust. Another parameter, $\mathrm{c} R^{2}{ }_{p}$ is also calculated which should be more than 0.5 for passing this test.

$$
C R_{P}=R\left(R^{2}-\left(\text { average } R_{r}\right)^{2}\right)^{\frac{1}{2}}
$$

Quality assurance of the model: Internal and external

\begin{tabular}{|c|c|c|}
\hline Symbol & Name & Value \\
\hline $\mathrm{R}^{2}$ & Co-efficient of determination & $\geq 0.6$ \\
\hline $\mathrm{P}_{(95 \%)}$ & $\begin{array}{l}\text { Confidence interval at } \\
\text { confidence level }\end{array}$ & $<0.05$ \\
\hline $\mathrm{Q}^{2}$ & Cross-Validation Co-efficient & $\geq 0.5$ \\
\hline $\mathrm{R}^{2}-\mathrm{Q}^{2}$ & Difference between $\mathrm{R}^{2}$ and $\mathrm{Q}^{2}$ & $\leq 0.3$ \\
\hline $\begin{array}{l}\mathrm{N}_{\text {(ext, and }} \\
\text { test set) }\end{array}$ & $\begin{array}{l}\text { Minimum number of external and test } \\
\text { set }\end{array}$ & $\geq 05$ \\
\hline $\mathrm{R}_{\text {ext. }}^{2}$ & $\begin{array}{l}\text { Co-efficient of determination of } \\
\text { external and test set }\end{array}$ & $\geq 0.5$ \\
\hline
\end{tabular}
validations parameters are used to assess the reliability and predictive ability of a QSAR model. Table 2 gives the general minimum requirement values for the assessment of a QSAR model (Veerasamy et al., 2011).

Table 2 - General minimum recommended value for the evaluation of QSAR model.

Molecular docking studies: Protein-Ligand docking studies on 35 Biscoumarin derivatives were performed to study the interaction between the binding pocket of $\alpha$-glucosidase enzyme and the ligands on Hp G62 computer system, with Intel ( Core $^{\mathrm{TM}}$ i3 Dual CPU, M330@2.13 GHz 2.13GHz, 4GB of RAM using Auto dock vina 4.2 of pyrex virtual screening software, Chimera version 1.10 .2 and Discovery studio software.

Ligands Preparation: The optimized structures of the compounds from Spartan'14 were saved as PDB file format for the docking studies(Abdulfatai et al., 2017). Figure1 shows the $3 \mathrm{D}$ structure of the prepared ligand.

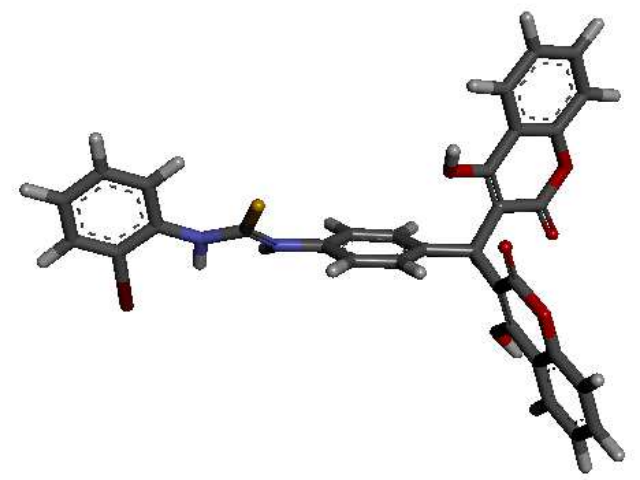

Figure 1 - 3D structure of the prepared Ligand.

Preparation of receptor: The 3D structure of the receptor (Saccharomyces cerevisiae isomaltase) with the PDB code 3AJ7 was retrieved from Protein Databank (PDB). Discovery studio software was to prepare the receptor by removing water molecules and cofactors (Veerasamy et al., 2011) and save as PDB file format. Figure 2 shows the 3D structure of the prepared Receptor. 


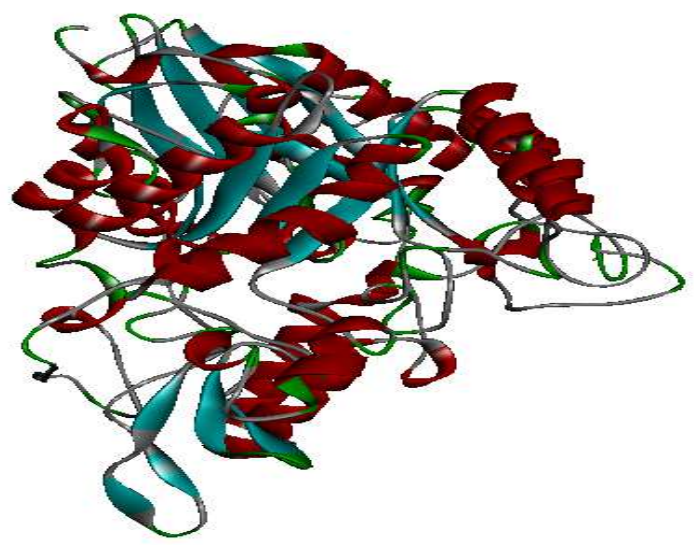

Figure 2 - 3D structure of the prepared Receptor.

Docking of the ligands with the receptor using Autodock version 4.0 of pyrex software: The docking of ligands (Biscoumarin derivatives) with the receptor $(\alpha$ glycosidase) was done using Autodock version 4.0 of pyrex software (Trott and Olson, 2010). Chimera 1.10.2 software was used to build the complex (ligand-receptor) since the receptor and the ligand decoupled after carrying out docking with the autodock vina of pyrex. The ligand-receptor were visualized to view their interactions utilizing Discovery studio visualizer.

\section{RESULT AND DISCUSSION}

\subsection{QSAR results.}

Genetic Function Algorithm (GFA) of material studio software was employed to generate four QSAR models. Out of these four models, based on the internal assessment statistical parameters for QSAR models, model 1 was chosen as the best model. The best model equation is given below:

Model 1

$$
\begin{aligned}
\text { pIC50 }=0.288289720 \text { HBD Cnt } \\
\\
-0.018409794 \text { AATS8m } \\
+4.204618239 \text { AATSC5i } \\
-0.003870369 \text { ECCEN } \\
+8.911608832 \text { MWC5 }-65.32884998
\end{aligned}
$$

$\mathrm{R}^{2}=0.9144 \mathrm{R}_{\text {adj }}^{2}=0.8929, \mathrm{Q}^{2}$ LOO $=0.8582, \mathrm{~N}$ trng $=26, \mathrm{R}_{\text {test }}^{2}=$ $0.614745, \mathrm{~N}_{\text {test }}=9$

The positive coefficient of the descriptors in model 1 such as HBD Count. (Hydrogen bond donor count), AATSC5i (Average centered Broto-Moreau autocorrelation - lag 5 / weighted by first ionization potential) and MWC5 (Molecular walk count of order $5(\ln (1+\mathrm{x}))$ will increase the inhibitory activities of these Biscoumarins against $\alpha$-glycosidase enzymes responsible for the breakdown of carbohydrate. Furthermore, the negative coefficient of AATS8m (Average Broto-Moreau autocorrelation - lag 8 / weighted by mass) and ECCEN (Eccentric connectivity index) implies that the inhibitory activities of these Biscoumarins against $\alpha$-glycosidase will be more with the decrease in such descriptors. Table 3 gives the

\begin{tabular}{|c|c|c|c|}
\hline S/no & Name & Description & Class \\
\hline 1 & HBDCnt. & $\begin{array}{l}\text { Hydrogen bond donor } \\
\text { count. }\end{array}$ & $2 \mathrm{D}$ \\
\hline 2 & AATS8m & $\begin{array}{l}\text { Average Broto-Moreau } \\
\text { autocorrelation - lag } 8 \text { / } \\
\text { weighted by mass }\end{array}$ & $2 \mathrm{D}$ \\
\hline 3 & AATSC5i & $\begin{array}{l}\text { Average centered } \\
\text { Broto-Moreau } \\
\text { autocorrelation - lag } 5 \text { / } \\
\text { weighted by first } \\
\text { ionization potential }\end{array}$ & $2 \mathrm{D}$ \\
\hline 4 & ECCEN & $\begin{array}{l}\text { Eccentric connectivity } \\
\text { index }\end{array}$ & $2 \mathrm{D}$ \\
\hline 5 & MWC5 & $\begin{array}{l}\text { Molecular walk count } \\
\text { of order } 5(\ln (1+x)\end{array}$ & $2 \mathrm{D}$ \\
\hline
\end{tabular}
symbols, descriptions, and classes of the descriptors used in the model.

Table 3 - List of the descriptors, their description, and classes for model 1

The high calculated $\mathrm{R}^{2}$ value $(0.9144), \mathrm{R}_{\text {adj }}$ value $(0.8929)$ and $\mathrm{Q}_{\mathrm{cv}}{ }^{2} \mathrm{LOO}$ value $(0.8582)$ of the model indicates a good internal assessment of the model. $\mathrm{R}^{2}$ for the external assessment of the model was also calculated for the test set containing $25 \%$ of the data and was found to be 0.6147 . Table 4 and 5 give the external validation and calculation of the predictive $\mathrm{R}^{2}$ of model 1 .

Table 6 present the experimental and predicted activities of $\alpha$-glycosidase inhibitors as a potent anti-diabetic and the residual values. The high predictive power of the model is indicated by the low residual value between experimental and predicted activities

Correlation matrix of the descriptors in the best model: A correlation matrix was performed on the descriptors that appear in the best model and found to be highly correlated which means that the descriptors used to build the model are very good. Table 7 gives the result of the correlation matrix.

Table 4 - External validation of model 1.

\begin{tabular}{ccccccccc} 
S/No. & pIC 50 & HBD Cnt. & AATS8m & AATSC5i & ECCEN & MWC5 & Yprd & Yprd-Yobs \\
\hline 3b & 1.59 & 4 & 71.62441 & -0.09696 & 1331 & 8.120589 & 1.314125 & -0.27587 \\
7b & 1.96 & 4 & 68.58793 & -0.05797 & 1263 & 8.1277 & 1.860515 & -0.09948 \\
$11 \mathrm{~b}$ & 1.45 & 4 & 70.53864 & -0.08223 & 1265 & 8.121183 & 1.656818 & 0.206818 \\
15b & 1.64 & 4 & 65.44368 & -0.08198 & 1331 & 8.120589 & 1.490894 & -0.14911 \\
$19 \mathrm{~b}$ & 2.59 & 2 & 78.37368 & -0.13035 & 797 & 8.111028 & 2.454472 & -0.13553 \\
23b & 2.05 & 3 & 89.98194 & -0.11343 & 734 & 8.034955 & 2.166103 & 0.116103 \\
27b & 2.11 & 2 & 85.45815 & -0.08617 & 797 & 8.111028 & 2.509814 & 0.399814 \\
31b & 1.83 & 2 & 75.47388 & -0.19613 & 734 & 8.027803 & 1.733458 & -0.09654 \\
35b & 1.88 & 2 & 88.52307 & -0.13147 & 717 & 7.996654 & 1.553316 & -0.32668 \\
\hline
\end{tabular}


Table 5 - Calculation of the predictive $R^{2}$ of model 1.

\begin{tabular}{ccccc} 
S/No. & $\left(\mathrm{Y}_{\text {prd }}-\mathrm{Y}_{\text {obs }}\right)^{2}$ & $\overline{\mathrm{Y}}_{\text {trng }}$ & $\mathrm{Y}_{\text {obs }}-\overline{\mathrm{Y}}_{\text {trng }}$ & $\left(\mathrm{Y}_{\text {obs }}-\overline{\mathrm{Y}}_{\text {trng }}\right)^{2}$ \\
3b & 0.076107 & 1.7258 & -0.1358 & 0.018442 \\
7b & 0.009897 & 1.7258 & 0.2342 & 0.05485 \\
11b & 0.042774 & 1.7258 & -0.2758 & 0.076066 \\
15b & 0.022233 & 1.7258 & -0.0858 & 0.007362 \\
19b & 0.018368 & 1.7258 & 0.8642 & 0.746842 \\
23b & 0.01348 & 1.7258 & 0.3242 & 0.105106 \\
27b & 0.159851 & 1.7258 & 0.3842 & 0.14761 \\
31b & 0.00932 & 1.7258 & 0.1042 & 0.010858 \\
35b & 0.106722 & 1.7258 & 0.1542 & 0.023778 \\
& $\Sigma\left(\mathrm{Y}_{\text {prd }}-\mathrm{Y}_{\text {obs }}\right)^{2}=0.4588$ & & & $\Sigma\left(\mathrm{Y}_{\text {obs }}-\overline{\mathrm{Y}}_{\text {trng }}\right)^{2}=1.1909$ \\
& & & $\mathrm{R}^{2}=(1-0.4588 / 1.1909)=0.614745$ \\
\hline
\end{tabular}

Table 6 - Comparison of Experimental $\left(\mathrm{pIC}_{50}\right)$, Predicted (pIC $\left.\mathrm{C}_{50}\right)$ and Residual of Model 1.

\begin{tabular}{|c|c|c|c|}
\hline S/no & $\mathrm{pIC}_{50}$ & predicted $\mathrm{pIC}_{50}$ & Residual \\
\hline 1 & 1.57 & 1.572693 & -0.00269 \\
\hline 2 & 1.55 & 1.524139 & 0.025861 \\
\hline 4 & 2.02 & 1.883073 & 0.136927 \\
\hline 5 & 1.4 & 1.468213 & -0.06821 \\
\hline 6 & 1.13 & 1.189773 & -0.05977 \\
\hline 8 & 1.74 & 1.795393 & -0.05539 \\
\hline 9 & 1.73 & 1.645647 & 0.084353 \\
\hline 10 & 1.7 & 1.715159 & -0.01516 \\
\hline 12 & 1.43 & 1.420691 & 0.009309 \\
\hline 13 & 1.7 & 1.8595 & -0.1595 \\
\hline 14 & 1.89 & 1.863038 & 0.026962 \\
\hline 16 & 1.5 & 1.461293 & 0.038707 \\
\hline 17 & 1.71 & 1.683683 & 0.026317 \\
\hline 18 & 1.9 & 1.899039 & $9.61 \mathrm{E}-04$ \\
\hline 20 & 1.57 & 1.662324 & -0.09232 \\
\hline 21 & 1.72 & 1.817606 & -0.09761 \\
\hline 22 & 1.91 & 1.917366 & -0.00737 \\
\hline 24 & 1.92 & 1.879253 & 0.040747 \\
\hline 25 & 1.92 & 2.026843 & -0.10684 \\
\hline 26 & 1.76 & 1.730718 & 0.029282 \\
\hline 28 & 1.96 & 2.006411 & -0.04641 \\
\hline 29 & 1.22 & 1.170741 & 0.049259 \\
\hline 30 & 1.43 & 1.463729 & -0.03373 \\
\hline 32 & 2.35 & 2.288598 & 0.061402 \\
\hline 33 & 2.11 & 2.138544 & -0.02854 \\
\hline 34 & 2.03 & 1.786534 & 0.243466 \\
\hline
\end{tabular}

Table 7 - Pearson's correlation matrix of the descriptors in model 1.

\begin{tabular}{lrrrrr}
\hline & HBD Cnt. & AATS8m & AATSC5i & ECCEN & MWC5 \\
HBD Cnt. & 1 & & & & \\
AATS8m & -0.71498 & 1 & & & \\
AATSC5i & 0.690063 & -0.33956 & 1 & & \\
ECCEN & 0.931779 & -0.85799 & 0.68082 & 1 & \\
MWC5 & 0.599984 & -0.68793 & 0.711074 & 0.747915 & 1 \\
\hline
\end{tabular}

Figure 3 shows the plot of predicted activities of both training and test sets against Experimental activities, the reliability of model 1 was confirmed by high Linearity of this plot which indicates the high predictive power of the model.

The measure of the dispersion of standardized residual values from the Experimental activity $\left(\mathrm{pIC}_{50}\right)$ values is presented in Figure 4. The propagation of the errors on both sides of zero is an indication of the robustness of model 1

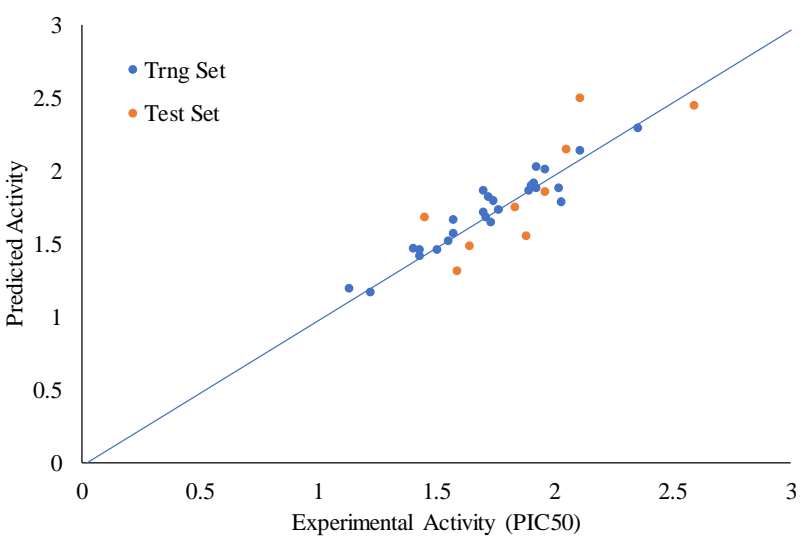

Figure 3 - The plot of the Experimental and Predicted activity of both the training and test sets of model 1. 


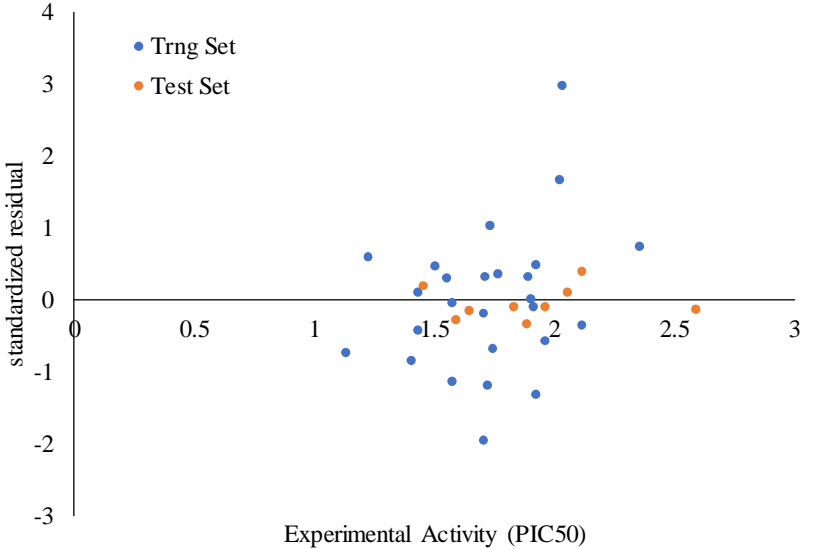

Figure 4 - The plot of the standardized residual and Experimental activity (pIC50) of model 1.

Williams plot of model 1: Figure 5 shows the Williams plot of the standardized residual against leverages of both the training and test sets of model 1. Four compounds of the test set were found to be influential because their leverage values are greater than the warning leverages $(\mathrm{h} *=0.692)$. This is because their molecular structure is different from other compounds of the dataset.

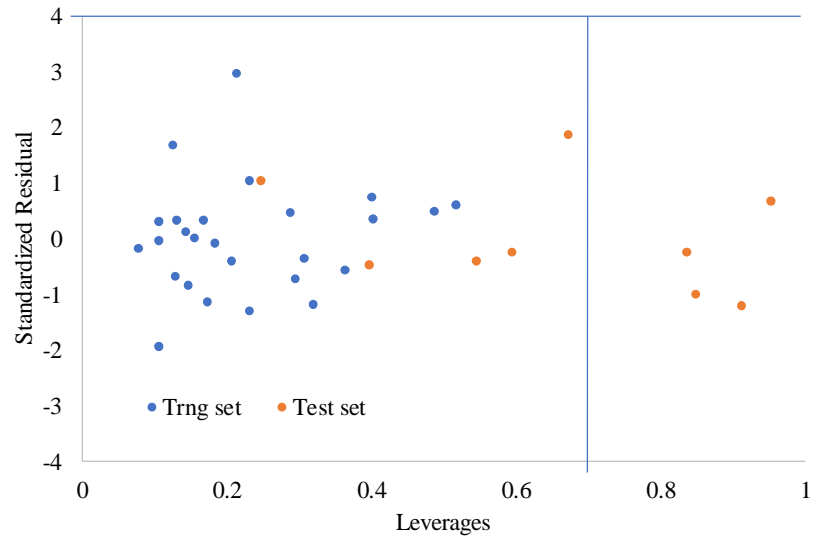

Figure 5 - Williams plot of the standardized residual and leverages of both the training and test sets of model 1.

Y-randomization test of model 1: The Yrandomization test presented in table 8 showed that the model is not obtained by chance it is robust and good because it has significantly low $R^{2}$ and $Q^{2}$ values for several trials and also ${ }^{\mathrm{C}} \mathrm{R}_{\mathrm{P}}^{2}$ value is greater than 0.5.

3.2 Results of molecular docking studies of the Biscoumarins derivatives.

Molecular docking studies of 35 Biscoumarin and Biscoumarin thiourea derivatives was carried out against $\alpha$ glucosidase to find out their docking scores and their interactions. Ligands with the best docking scores were presented in table 9 and the docking scores were found to correlate with their experimentally determined inhibitory activities. Ligand 16 with the best docking scores of -12.5 $\mathrm{kcal} / \mathrm{mol}$ showed hydrogen bond interaction with ASP352

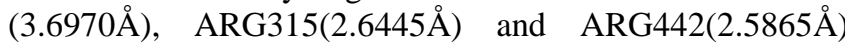
active sites. Also, it forms a hydrophobic interaction with HIS280, TYR158, LYS156, PRO312, ARG315, TYR72 and PHE178 active site of the receptor. In addition, it forms an electrostatic interaction with GLU277, ASP307,
ARG315, ARG442, ASP352, ASP69 and ASP215 residues. Figure 6 and 7 give the 3D, 2D and H-bond interaction between $\alpha$-glucosidase and ligand 16. From the docking studies, it is shown that ligand 16 has the highest docking scores and showed very good interaction with the active site residue of the receptor as compared to other ligands.
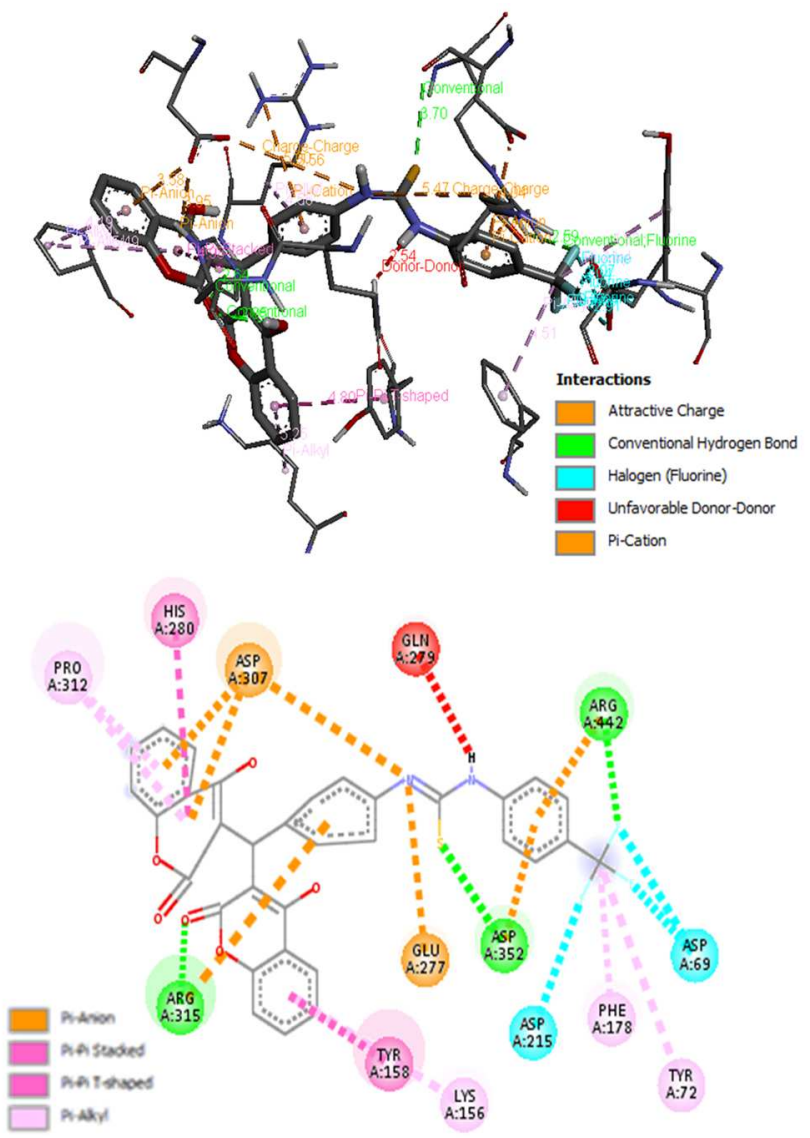

Figure 6-3D and 2D interaction between $\alpha$-glucosidase and Ligand 16.

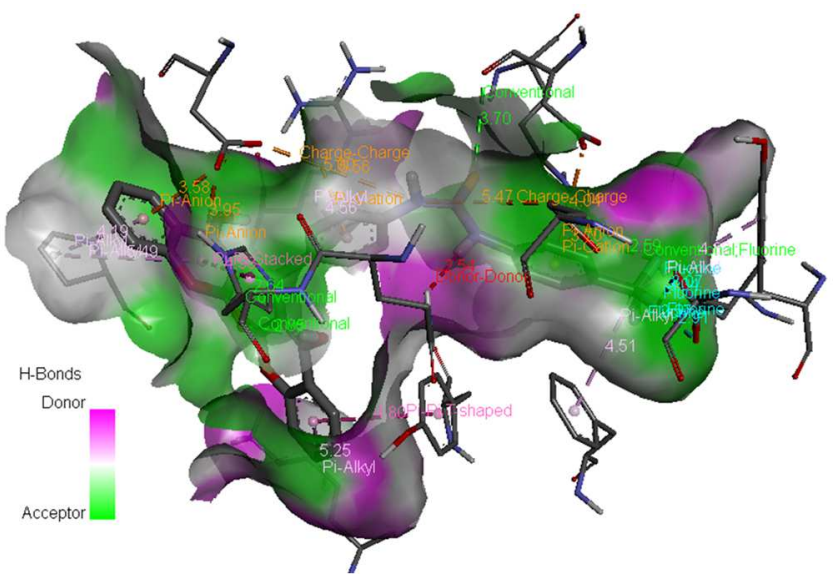

Figure 7 - The Hydrogen-bond interaction between ligand 16 and $\alpha$-glucosidase 
Table 8 - Result Y randomization test

\begin{tabular}{cccc}
\hline Model & $\mathrm{R}$ & $\mathrm{R}^{2}$ & $\mathrm{Q}^{2}$ \\
Original & 0.881884 & 0.777719 & 0.608842 \\
Random 1 & 0.649304 & 0.421596 & 0.069882 \\
Random 2 & 0.258633 & 0.066891 & -0.42333 \\
Random 3 & 0.218202 & 0.047612 & -0.63194 \\
Random 4 & 0.562411 & 0.316306 & -0.06344 \\
Random 5 & 0.1465 & -0.58996 \\
Random 6 & 0.497656 & 0.021462 & -0.20249 \\
Random 7 & 0.197324 & 0.247662 & -0.51371 \\
Random 8 & 0.459429 & 0.038937 & -0.15327 \\
Random 9 & 0.284061 & 0.211075 & -0.40922 \\
Random 10 & 0.489127 & 0.080691 & -0.11405 \\
Average : & Random Models Parameters & 0.239246 & \\
Average r ${ }^{2}:$ & 0.376265 & & \\
Average Q ${ }^{2}:$ & 0.169148 & & \\
cRp $^{2}:$ & -0.30315 & 0.703378 & \\
\hline
\end{tabular}

Table 9- Binding energy, hydrophobic interactions, Electrostatic/other interactions, Hydrogen bonds and Hydrogen bond distance of $\alpha$-glycosidase and the ligands with highest docking scores.

\begin{tabular}{|c|c|c|c|c|c|}
\hline $\begin{array}{l}\text { Ligand- } \\
\text { Receptor }\end{array}$ & $\begin{array}{c}\text { Binding } \\
\text { Energy }(\mathrm{kcal} / \mathrm{mol})\end{array}$ & Hydrophobic interaction & $\begin{array}{c}\text { Electrostatic } \\
\text { Interaction/Others }\end{array}$ & Hydrogen Bonds & $\begin{array}{l}\text { Hydrogen Bond } \\
\text { Distance }(\AA)\end{array}$ \\
\hline 1 & -11.4 & $\begin{array}{c}\text { TYR158, HIS280, LYS156 } \\
\text { and ARG315 }\end{array}$ & ASP307 & $\begin{array}{l}\text { THR310, SER311, } \\
\text { THR310 and ASP307 }\end{array}$ & $\begin{array}{l}2.5128,2.6980,3 \\
.5082 \text { and } 2.0744\end{array}$ \\
\hline 2 & -11.8 & $\begin{array}{c}\text { HIS280, SER15, TYR158, } \\
\text { VAL216, LYS156, } \\
\text { PRO312, ARG315 and } \\
\text { PHE178 }\end{array}$ & $\begin{array}{l}\text { GLU277, ASP307, } \\
\text { ASP215, ARG315, } \\
\text { ARG442, ASP307 } \\
\text { and ASP352, }\end{array}$ & $\begin{array}{c}\text { ASP352, GLN353, } \\
\text { ARG315 and ARG315 }\end{array}$ & $\begin{array}{c}3.0663,3.7505 \\
2.6071 \text { and } \\
2.68669\end{array}$ \\
\hline 5 & -12.0 & $\begin{array}{c}\text { TYR158, SER157, } \\
\text { LYS156, PRO312 and } \\
\text { ARG315 }\end{array}$ & $\begin{array}{l}\text { ARG31, GLU277, } \\
\text { ASP307 and } \\
\text { ASP352 }\end{array}$ & $\begin{array}{c}\text { SER311, ASP352, } \\
\text { GLU411, ARG315, } \\
\text { ARG315, ARG442 and } \\
\text { ASP215 }\end{array}$ & $\begin{array}{l}2.1412,3.5428, \\
3.6486,2.5651, \\
2.8086,2.3801 \\
\quad \text { and } 3.6394\end{array}$ \\
\hline 9 & -11.4 & $\begin{array}{l}\text { TYR158, ARG315, } \\
\text { LYS156 and ARG315 }\end{array}$ & $\begin{array}{l}\text { ASP307, ASP307 } \\
\text { and SER304 }\end{array}$ & HIS 280 & 4.1192 \\
\hline 16 & -12.5 & $\begin{array}{l}\text { HIS280, TYR158, } \\
\text { LYS156, PRO312, } \\
\text { ARG315, TYR72 and } \\
\text { PHE178 }\end{array}$ & $\begin{array}{l}\text { GLU277, ASP307, } \\
\text { ARG315, } \\
\text { ARG442, ASP352, } \\
\text { ASP69 and } \\
\text { ASP215 }\end{array}$ & $\begin{array}{c}\text { ASP352, ARG315 and } \\
\text { ARG442 }\end{array}$ & $\begin{array}{l}3.6970,2.6448 \\
\text { and } 2.5865\end{array}$ \\
\hline 17 & -11.8 & $\begin{array}{c}\text { HIS280, TYR158, } \\
\text { SER157, LYS156, } \\
\text { PRO312 and ARG315 }\end{array}$ & $\begin{array}{l}\text { GLU277, } \\
\text { ARG315, ARG442 } \\
\text { and ASP307 }\end{array}$ & $\begin{array}{c}\text { SER311, ASP352, } \\
\text { ARG315 and ARG315 }\end{array}$ & $\begin{array}{c}2.0858,3.1577 \\
2.592 \text { and } 2.8519\end{array}$ \\
\hline 24 & -11.0 & $\begin{array}{l}\text { SER157, PRO312, } \\
\text { LYS156, ARG315 and } \\
\text { TYR158 }\end{array}$ & ASP307 & $\begin{array}{c}\text { THR310, SER311 and } \\
\text { ARG315 }\end{array}$ & $\begin{array}{c}3.0061,2.2284 \\
\text { and } 2.5721\end{array}$ \\
\hline 30 & -11.4 & $\begin{array}{c}\text { HIS280, SER311, } \\
\text { PRO312, LYS156, } \\
\text { ARG315 and TYR158 }\end{array}$ & ASP307 & THR310 and ARG315 & 2.2917 and 2.5050 \\
\hline
\end{tabular}

\section{CONCLUSION}

QSAR and molecular docking studies of 35 compounds of Biscoumarin and Biscoumarin thiourea derivatives as $\alpha$-glucosidase inhibitors was performed. Density Functional Theory (DFT) method was employed for complete geometry optimization of the $\alpha$-glucosidase inhibitors. Genetic Function Algorithm (GFA) of the material studio was utilized to develop four models. Model 1 was found to be the best model with $\mathrm{R}^{2}=0.9144, \mathrm{R}^{2}$ adj $=$ $0.8929, \mathrm{Q}^{2}=0.8582$ and the external validation $\mathrm{R}^{2}$ pred $=$ 0.6147 . As a result of the negative and positive coefficient of the descriptors in the model, it indicates that decrease in descriptors with negative coefficients such as AATS8m and ECCEN with increase in HBD count, AATSC5i and MWC5 descriptors with positive coefficient will increase 
the inhibitory activity of these molecules against $\alpha$ glucosidase key enzymes responsible for the breaking down of carbohydrate. From the docking studies, it is shown that ligand 16 has the highest docking scores of $-12.5 \mathrm{kcal} / \mathrm{mol}$ and formed hydrogen bond, hydrophobic and electrostatic interactions with the active site of the receptor. The QSAR model and molecular docking results correlate with one another and give room for designing new $\alpha$-glucosidase inhibitors with better activity.

\section{A C K N O W LE D G M E N T S}

The authors sincerely acknowledge Ahmadu Bello University, Zaria for its technical support and Dr. Sani Uba for his advice in the cause of this research.

\section{R E F E R E N C E S}

ABDULFATAI, U.; UZAIRU, A.; \& UBA, S. In Silico Study Of Some Anticonvulsant Compounds. Scholars' Press Isbn: 978-3-330-65212-5, 2016.

ABDULFATAI, U.; UZAIRU, A.; \& UBA, S. Quantitative Structure-Activity Relationship And Molecular Docking Studies Of A Series Of Quinazolinonyl Analogues As Inhibitors Of Gamma Amino Butyric Acid Aminotransferase. Journal of Advanced Research, 8, 33-43, 2017.

ADENIJI, S. E.; UBA, S.; \& UZAIRU, A. Quantitative Structure-Activity Relationship And Molecular Docking Of 4-Alkoxy-Cinnamic Analogues As Anti-Mycobacterium Tuberculosis. Journal of King Saud University-Science, 2018.

AMIT, C.; PAYAL, C.; \& R.K, D. Qsar Study Of 2,4Dioxothiazolidine Antidiabetic Compounds, 2014.

ARTHUR, D. E.; UZAIRU, A.; MAMZA, P.; ABECHI, S. E.; \& SHALLANGWA, G. Insilco Study On The Toxicity Of Anti-Cancer Compounds Tested Against Molt-4 And P388 Cell Lines Using GaMlr Technique. Beni-Suef University Journal of Basic And Applied Sciences, 5, 320-333, 2016.

AZIZ, M. T. A.; EL-ASMAR, M. F.; REZQ, A. M.; MAHFOUZ, S. M.; WASSEF, M. A.; FOUAD, H. H.; AHMED, H. H.; \& TAHA, F. M. The Effect Of A Novel Curcumin Derivative On Pancreatic Islet Regeneration In Experimental Type-1 Diabetes In Rats (Long-Term Study). Diabetology \& Metabolic Syndrome, 5, 75, 2013.

BIBI, S. \& SAKATA, K. Current Status Of ComputerAided Drug Design For Type 2 Diabetes. Current Computer-Aided Drug Design, 12, 167-177, 2016.

BOUKARAI, Y.; KHALIL, F.; \& BOUACHRINE, M. Qsar Study Of Flavonoid Derivatives As In Vitro Inhibitors Agents Of Aldose Reductase (Alr2) Enzyme For Diabetic Complications, 2017.

JALALI-HERAVI, M.; \& KYANI, A. Use Of ComputerAssisted Methods For The Modeling Of The Retention Time Of A Variety Of Volatile Organic Compounds: A Pca-Mlr-Ann Approach. Journal Of Chemical Information And Computer Sciences, 44, 1328-1335, 2004.

KAVITHA， S.; KANNAN， K.; \& GNANAVEL， S. Synthesis, Characterization And Biological Evaluation Of Novel 2, 5 Substituted-1, 3, 4
Oxadiazole Derivatives. Saudi Pharmaceutical Journal, 25, 337-345, 2017.

KHAN, K. M.; RAHIM, F.; WADOOD, A.; KOSAR, N.; TAHA, M.; LALANI, S.; KHAN, A.; FAKHRI, M. I.; JUNAID, M.; \& REHMAN, W. Synthesis And Molecular Docking Studies Of Potent AGlucosidase Inhibitors Based On Biscoumarin Skeleton. European Journal of Medicinal Chemistry, 81, 245-252, 2014.

LI, W.; ZHENG, H.; BUKURU, J.; \& DE KIMPE, N. Natural Medicines Used In The Traditional Chinese Medical System For Therapy Of Diabetes Mellitus. Journal Of Ethnopharmacology, 92, 121, 2004.

TAHA, M.; ISMAIL, N. H.; LALANI, S.; FATMI, M. Q.; SIDDIQUI, S.; KHAN, K. M.; IMRAN, S.; \& CHOUDHARY, M. I. Synthesis Of Novel Inhibitors Of A-Glucosidase Based On The Benzothiazole Skeleton Containing Benzohydrazide Moiety And Their Molecular Docking Studies. European Journal Of Medicinal Chemistry, 92, 387-400, 2015.

TALELE, T. T.; KHEDKAR, S. A.; \& RIGBY, A. C. Successful Applications Of Computer-Aided Drug Discovery: Moving Drugs From Concept To The Clinic. Current Topics In Medicinal Chemistry, 10, 127-141, 2010.

TROPSHA, A.; GRAMATICA, P.; \& GOMBAR, V. K. The Importance of Being Earnest: Validation Is The Absolute Essential For Successful Application And Interpretation Of Qspr Models. Molecular Informatics, 22, 69-77, 2003.

TROTT, O.; \& OLSON, A. J. Autodock Vina: Improving The Speed And Accuracy Of Docking With A New Scoring Function, Efficient Optimization, And Multithreading. Journal of Computational Chemistry, 31, 455-461, 2010.

VEERASAMY, R.; RAJAK, H.; JAIN, A.; SIVADASAN, S.; VARGHESE, C. P.; \& AGRAWAL, R. K. Validation Of Qsar Models-Strategies And Importance. International Journal Of Drug Design \& Discovery, 3, 511-519, 2011.

WANG, G.; PENG, Z.; WANG, J.; LI, J.; \& LI, X. Synthesis And Biological Evaluation Of Novel 2, 4, 5-Triarylimidazole-1, 2, 3-Triazole Derivatives Via Click Chemistry As A-Glucosidase Inhibitors. Bioorganic \& Medicinal Chemistry Letters, 26, 5719-5723, 2016a.

WANG, G.; PENG, Z.; WANG, J.; LI, J.; \& LI, X. Synthesis, Biological Evaluation And Molecular Docking Study Of N-Arylbenzo [D] Oxazole-2Amines As Potential A-Glucosidase Inhibitors. Bioorganic \& Medicinal Chemistry, 24, 53745379, 2016b.

ZAWAWI, N. K. N. A.; TAHA, M.; AHMAT, N.; ISMAIL, N. H.; WADOOD, A.; RAHIM, F.; \& REHMAN, A. U. Synthesis, In Vitro Evaluation And Molecular Docking Studies Of Biscoumarin Thiourea As A New Inhibitor Of A-Glucosidases. Bioorganic Chemistry, 63, 36-44, 2015. 